Classification

Physics Abstracts

$61.16 \mathrm{D}-82.80-82.65$

\title{
High resolution electron microscopy of a used automobile cata- lytic converter
}

\author{
Jan-Olle Malm and Jan-Olov Bovin
}

National Center for HREM, Dept. of Inorganic Chemistry 2, Chemical Center, P.O. Box 124, S-221 00 Lund, Sweden

(Received October 01, 1990; accepted January 10, 1991)

\begin{abstract}
Résumé. - Ce travail consiste en l'étude d'un pot d'échappement catalytique automobile par microscopie électronique principalement, et également par diffraction $\mathrm{X}$ sur poudres et microanalyse $\mathrm{X}$ par dispersion d'énergie. Ce pot d'échappement a été en service durant $80000 \mathrm{~km}$ sur une automobile courante dont une partie de la consommation était constituée d'essence au plomb. Le support a pu étre identifié comme $\mathrm{Mg}_{2} \mathrm{Al}_{4} \mathrm{Si}_{5} \mathrm{O}_{18}$ (Cordiérite $\alpha$ ou $\beta$ ). La contamination par le plomb a été detectée sur tout le support mais à plus forte concentration dans des agglomérats en surface de la cordiérite. Des petites particules de plombs ont été identifiées. Les métaux actifs ( $\mathrm{Pt}$ et $\mathrm{Rh}$ ) ont été principalement reconnus sous la forme de particules frittées $(>10 \mathrm{~nm})$ composées de Pt et Rh. Une quantité importante, surprenante de $\mathrm{Rh}$ a été mise en évidence dans ces particules $(\mathrm{Rh} / \mathrm{Pt} \geq 1)$. Dans de rares cas, il a été possible de reconnaître des particules de Pt ou de Rh de taille initiale $(\simeq 2 \mathrm{~nm})$.
\end{abstract}

\begin{abstract}
This work is a study of a used automobile catalytic converter using mainly electron microscopy but also techniques such as x-ray powder diffraction, energy dispersive x-ray spectroscopy (EDS) and image simulation. The catalytic converter was used for $\approx 80000 \mathrm{~km}$ in an ordinary car and partly with leaded fuel. The monolith could be identified as $\mathrm{Mg}_{2} \mathrm{Al}_{4} \mathrm{Si}_{5} \mathrm{O}_{18}(\alpha$-or $\beta$-cordierite). The lead contamination was detected all over the monolith but with a higher concentration in agglomerates on the cordierite surface. Small particles of elementary lead could be identified. The active metals ( $\mathrm{Pt}$ and $\mathrm{Rh}$ ) were mainly found as sintered particles $(>10 \mathrm{~nm})$ composed of both $\mathrm{Pt}$ and $\mathrm{Rh}$. An unexpectedly high amount of $\mathrm{Rh}$ was found in these particles $(\mathrm{Rh} / \mathrm{Pt}$ ratio $\geq 1)$. It was in some rare cases possible to image $\mathrm{Pt}$ or $\mathrm{Rh}$ particles with the initial size $(\approx 2 \mathrm{~nm})$.
\end{abstract}

\section{Introduction.}

In the search for thorough knowledge of catalytic reactions and their mechanisms it is an important task to gather information about the composition of the phases present in catalytic systems. It is equally important to study the active catalysts as the used, inactive, degraded and/or poisoned ones. The scope of this study is to contribute to this field. One of the few techniques that allows us to simultaneously do phase identifications of nanometer sized particles and image the surfaces 
of the particles at atomic scale is high resolution electron microscopy (HREM). This technique, in combination with microanalysis, has in this study been applied to a used automobile catalytic converter in order to increase our knowledge of what actually happens to the catalytic converter when it is used in an ordinary car.

\section{Experimental.}

The sample originates from a catalytic converter used for several years in an ordinary car. The catalyst has been used for approximately $80000 \mathrm{~km}$ and it should be pointed out that it has been used partly with leaded fuel, i.e. the catalyst has been poisoned with lead. This preparation technique of course leaves some questions about initial composition, reaction conditions etc. unanswered, but nevertheless it is interesting to study the properties and the composition of the used catalyst. In order to prepare the microscopy specimens, parts of the monolith were crushed and ground in an agate mortar. The powder was then dispersed in methanol and one drop of the dispersion was placed on a holey carbon grid.

The high resolution micrographs were obtained with a JEM-4000EX with a structural resolution better than $0.16 \mathrm{~nm}\left(C_{\mathrm{s}}=1.0 \mathrm{~mm}\right)$. The microscope is equipped with a Gatan TV-camera with an image intensifier. Some low magnification micrographs and the EDS analyses were done with a JEM-2000FX equipped with a Link AN10000 energy dispersive x-ray spectrometer. Image simulations and other calculations were done with the software packages SHRLI [1] and EMS [2].

\section{Discussion.}

In identifying the support material several techniques were used such as $\mathrm{x}$-ray powder diffraction, electron diffraction, high resolution image simulation and elementary analysis. It could be shown that the chemical composition was $\mathrm{Mg}_{2} \mathrm{Al}_{4} \mathrm{Si}_{5} \mathrm{O}_{18}$. This material crystallizes in two very closely related structures, 1.e. $\alpha$ - and $\beta$-cordierite ( $\alpha$-cordierite also being known as indialite).

The $\beta$-cordierite crystallizes in an orthorombic space group $(\mathrm{Cccm})$ and the $\alpha$-cordierite in a hexagonal one $\left(\mathrm{P}_{6} / \mathrm{mcc}\right)$. The $\alpha$-cordierite is isostructural with beryl and has a completely disordered array of $\mathrm{Al}$ and $\mathrm{Si}$ in the six membered rings whereas $\beta$-cordierite is ordered in this respect giving a lower symmetry. The monolith has in this study been used as an internal standard for magnification in order to simplify the determination of different phases present in the catalyst. The metric differences between the two $\mathrm{Mg}_{2} \mathrm{Al}_{4} \mathrm{Si}_{5} \mathrm{O}_{18}$ structures are small. This can be shown by a comparison of the orthorombic cell in $\beta$-cordierite with the equivalent calculated orthorombic cell in $\alpha$-cordierite. The cell parameters for $\beta$-cordierite are $a=0.972, b=1.71$ and $c=0.934 \mathrm{~nm}$ whereas the transformed parameters for the $\alpha$-cordierite are $a=0.977, b=1.69$ and $c=0.935 \mathrm{~nm}$. The differences are on the limit of what can be measured in a high resolution image. This means that it is still possible to use the material as an internal standard even though both structures might be present in the monolith. In some favourable situations it is also possible to distinguish between the two phases (due to the symmetry relations in the images) giving no ambiguity in the determination of the magnification (Fig. 1b). Figure 1a shows a typical high resolution image of $a$-cordierite viewed along the [001] direction. EDS analyses of the monolith (see e.g. the marked area in Fig. 2) confirm the composition $\left(\mathrm{Mg}_{2} \mathrm{Al}_{4} \mathrm{Si}_{5} \mathrm{O}_{18}\right)$ but have a tendency to give a slightly higher amount of aluminium than expected due to the washcoat $\left(\mathrm{Al}_{2} \mathrm{O}_{3}\right)$.

The study of a catalyst used under non-controlled conditions of course reveals a variety of contituents with different elementary compositions, sizes and shapes. Here we have chosen to focus our interest on the active metals (Pt and $\mathrm{Rh}$ ) and on the lead contamination. Other elements 


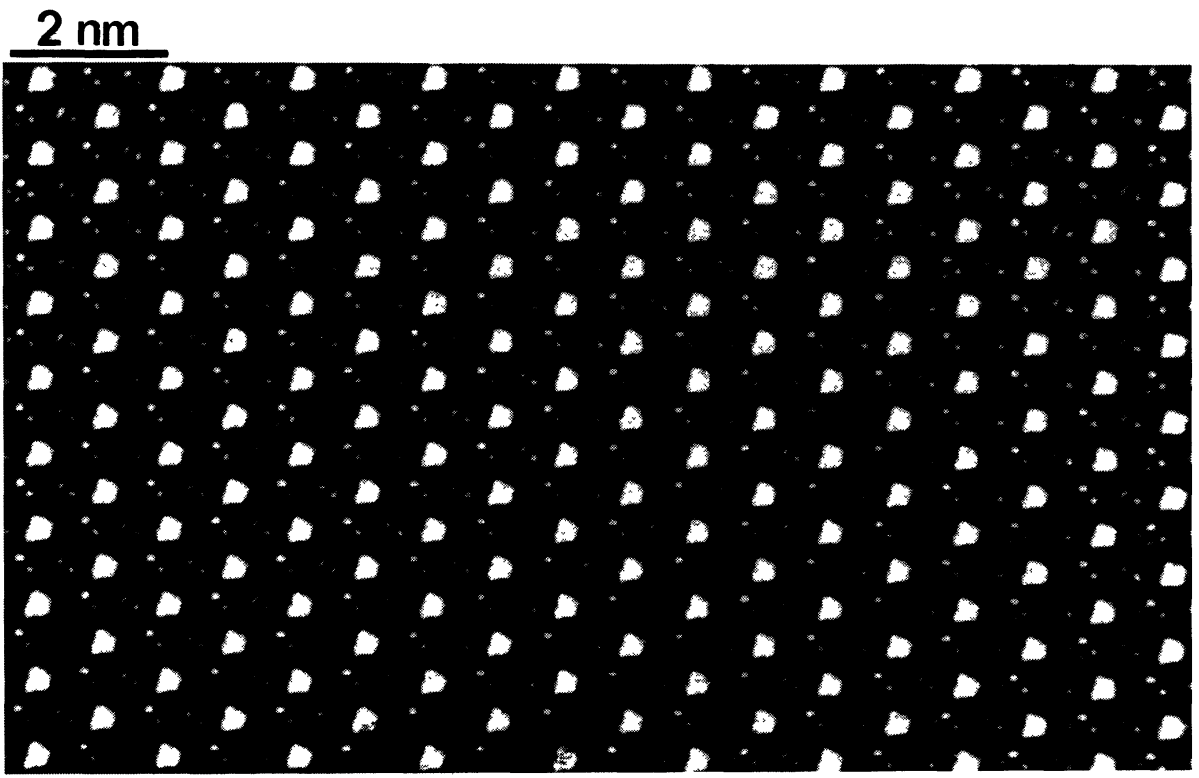

a)

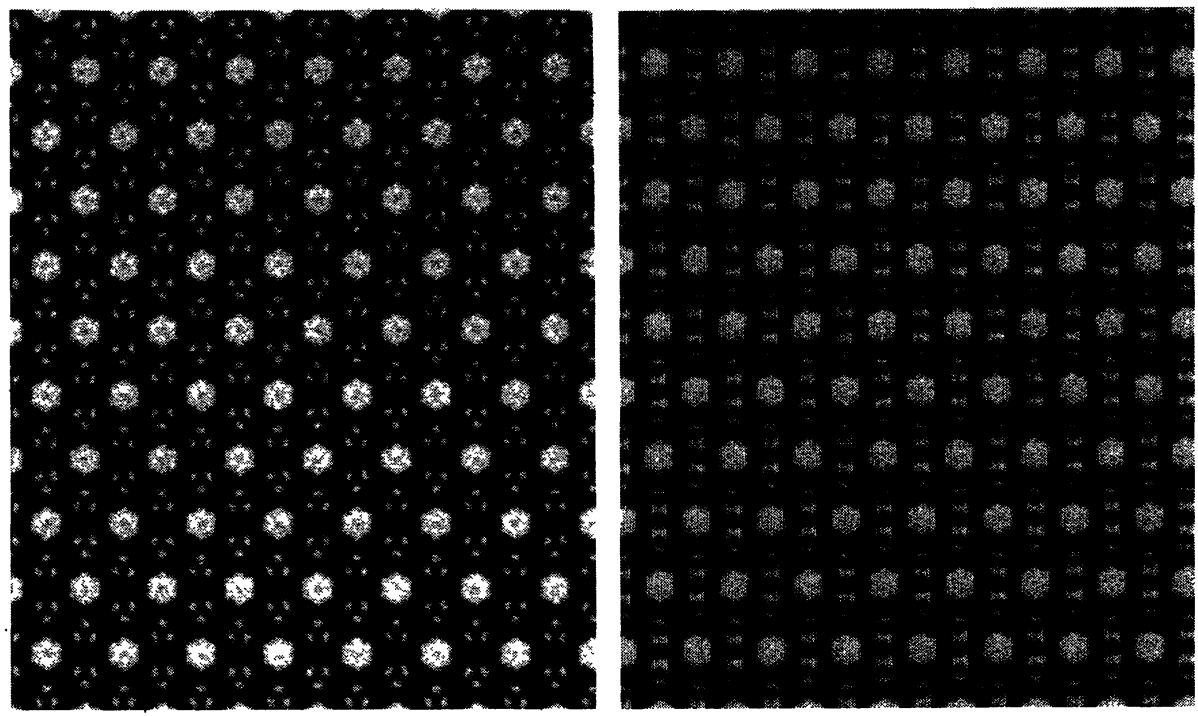

b)

Fig. 1. - Figure a shows a high resolution image of the monolith, in this case $\alpha$-cordierite, viewed along the [001] direction. In figure $b$ high resolution image simulations of the two cordierite structures viewed in corresponding directions, are presented. The left one is an image of $\alpha$-cordierite and the right simulation is of the $\beta$-phase. Both simulations are made at Scherzer defocus and with the electrooptical parameters for the JEM 4000EX used. A comparison of the simulated images shows the possibility to distinguish between the two phases using HREM. 
present with a significant amount in the catalyst are $\mathrm{Ce}, \mathrm{Fe}$, and $\mathrm{Ni}$. Lead contamination due to the use of leaded fuel can be found more or less all over the catalyst. The highest concentrations are present in particles or agglomerates situated on the cordierite surface (Fig. 2).

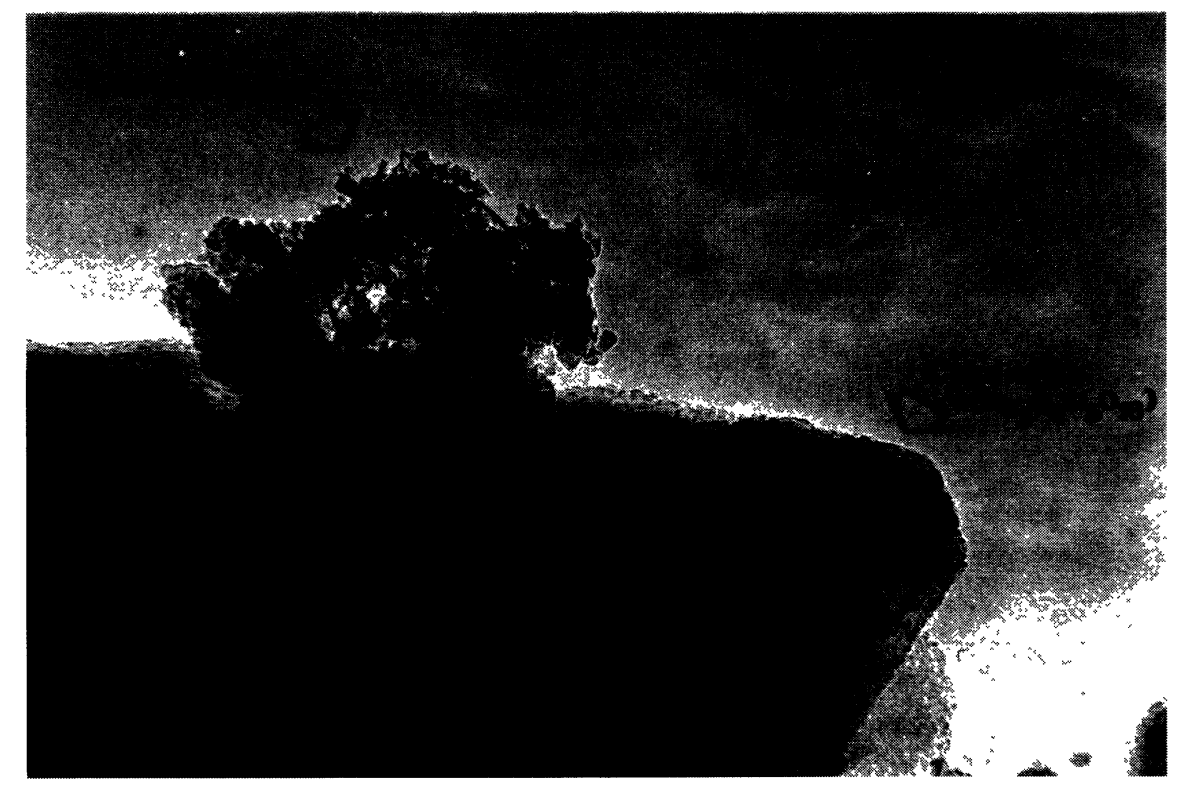

Fig. 2. - Low magnification micrograph of the monolith showing a contamination particle containing $\mathrm{Pb}$, $\mathrm{Al}, \mathrm{Ce}$ and $\mathrm{Ni}$ and an almost contamination free cordierite area.

These agglomerates (Fig. 2) have diameters varying from less than $100 \mathrm{~nm}$ up to many hundreds of nanometers. It is not only the lead which is present in comparatively high concentration in these agglomerates. There is also a high content of aluminium suggesting that the washcoat has been affected. Apart from these two elements nickel and cerium are also frequently found in these contamination particles on the cordierite surface.

The contamination particles are multiphase as can easily be shown by HREM. By combining several techniques such as EDS, electron diffraction and image simulation with previous knowledge of how different materials behave in the electron beam it is possible to identify some of the phases. On these agglomerates small crystalline particles can be found which in high resolution show the typical features of fcc packing (see Fig. 4). Using the support material as an internal standard it can be shown that the lattice parameters of these particles are very close to those of elementary lead (cf. Fig. 3).

These particles show the same behaviour in the electron beam as has been shown for several metals regarding mobility and structural rearrangements [3,4 and refs. therein]. Also the image simulations are consistent with the conclusion that elementary lead is present. Lead oxides are most likely also present in the used catalyst but mixtures of the pure oxides and the possibility of mixed oxides make phase determination a difficult task.

The EDS spectra from the catalyst confirm the presence of the active metals rhodium and platinum. These two metals can basically be identified in two forms. Either as big coalesced particles or as the original small particles. To unambiguously determine the composition of particles by 


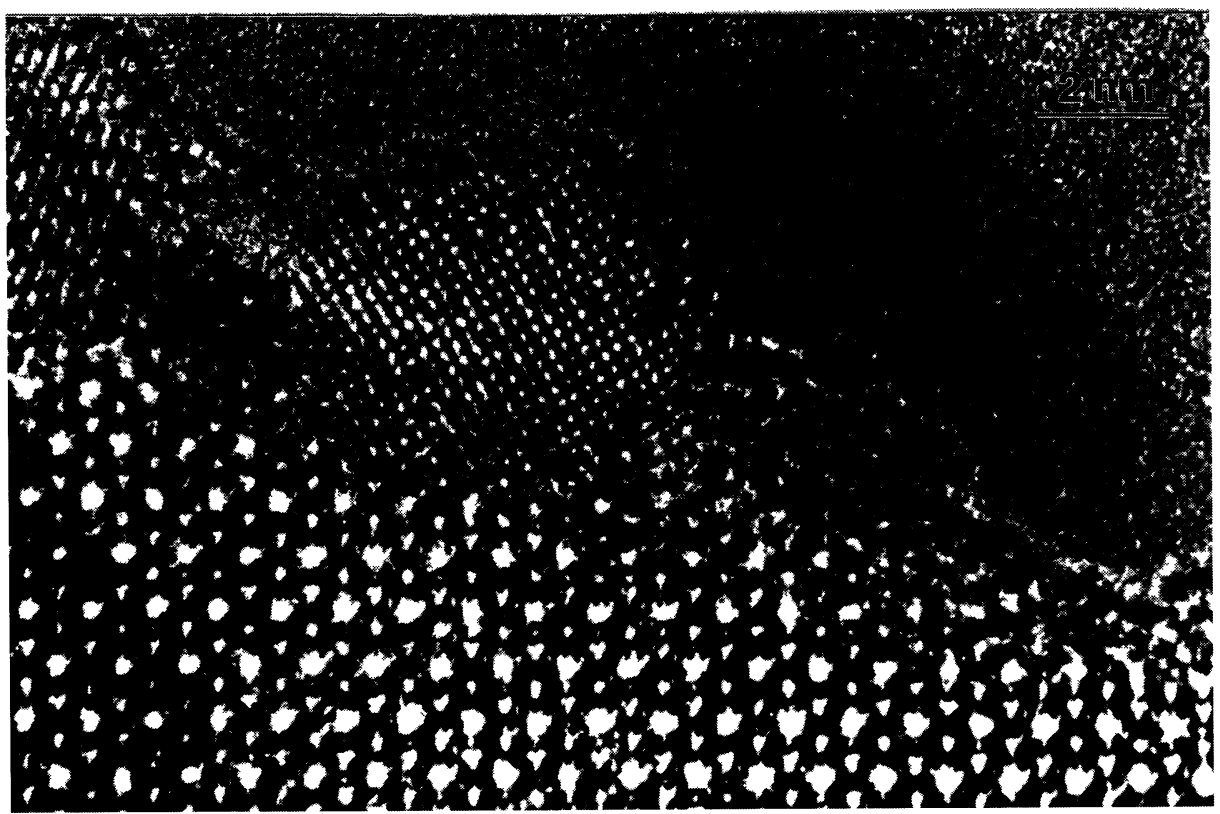

Fig. 3. - This high resolution micrograph shows a small particle situated on the surface of a cordierite crystal ([001] direction). The lattice spacings of the particle are consistent with the spacing of elementary lead viewed along the $[100]$ direction.

EDS is not straightforward. It is though possible to draw some conclusions if the particle is as large as the electron beam diameter or larger. In the catalytic converter particles with high contrast and width diameters ranging from ten to several tens of nanometers can be found (Fig. 5). As the beam diameter in this case could be reduced to $<30 \mathrm{~nm}$ while still obtaining a significant $\mathrm{x}$-ray signal the approximate composition of these particles could be determined.

It was found that these particles were mixtures of platinum and rhodium. To keep the costs down producers of automobile catalytic converters have strived to keep the $\mathrm{Rh} / \mathrm{Pt}$ ratio low. However it is possible to find $\mathrm{Rh} / \mathrm{Pt}$ ratios approaching and exceeding one in many of these particles. Thus there has been an enrichment of rhodium in these particles during the use of the catalyst. This observation is in contrast to some previous reports [5] which show a higher sintering rate for platinum during thermal aging resulting in a decreased $\mathrm{Rh} / \mathrm{Pt}$ ratio in sintered particles. Since the catalyst in our study has been used in a car for several thousands of kilometers during a period of $\approx 6$ years, the comparison with model experiments should be done with great care. Discussions of diffusion rate and possible interaction of $\mathrm{Rh}$ with the alumina washcoat [6] might not be valid under these conditions.

Though the catalyst has been heavily used it is still possible to find metal particles of the expected initial size $(\approx 2 \mathrm{~nm})$ even if they are rare. It was not possible to find areas covered with such small particles but single particles could be imaged.

Using the cordierite as an internal standard it can be shown that the lattice spacings in these small particles are consistent with those of the active metals even though it is hardly possible to distinguish between platinum $\left(a_{\mathrm{ccp}}=0.392 \mathrm{~nm}\right)$ and rhodium $\left(a_{\mathrm{ccp}}=0.380 \mathrm{~nm}\right)$ this way . However in some cases it is possible to make reliable guesses as to what kind of particle is being imaged. This can be done using previous knowledge of how the two metals are usually affected by 


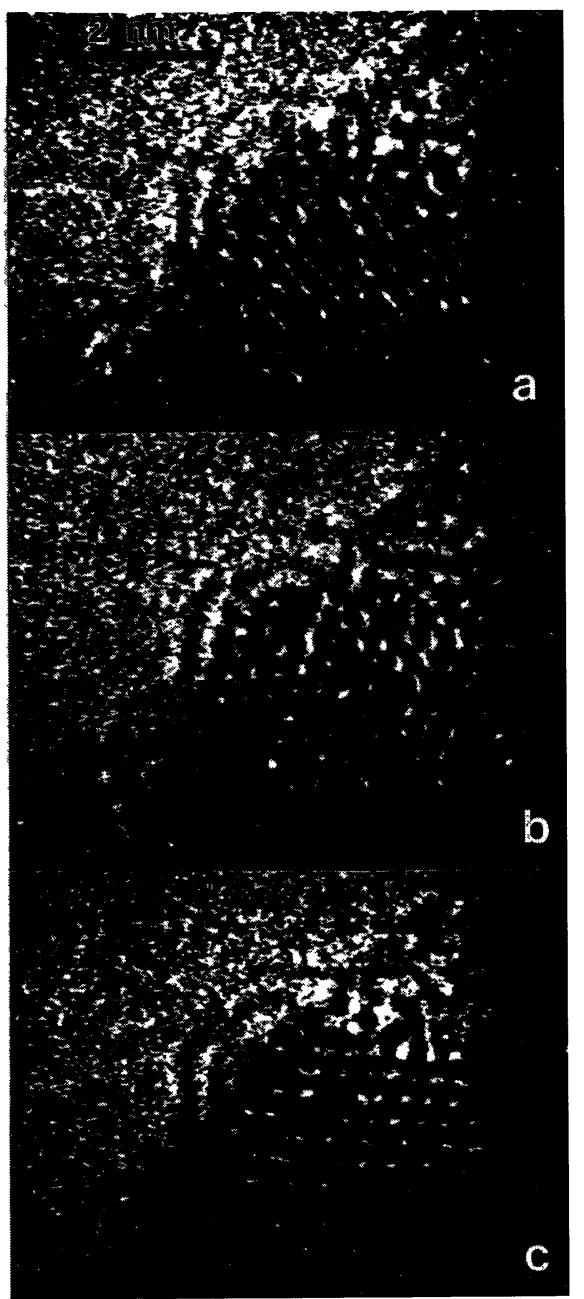

Fig. 4. - This high resolution sequence is taken from a video recording and shows a small lead particle moving under influence of the electron beam. The appearing and disappearing of twinning in the particle when observed for several minutes confirms that the particle rearranges its structure.

the beam in the electron microscope. The multiply twinned particle in figure 6 is situated firmly on the substrate and is rather stable in the electron beam. Some surface activity can be detected (see arrow) but otherwise there seems to be no anomalous surface structures. This indicates that it is a particle mainly consisting of platinum that is imaged. It has earlier been reported [7] that platinum shows some multiply twinning after oxidative heating which is consistent with this assumption.

\section{Conclusion.}

The occurrence of lead in the used catalytic converter after use with leaded fuel has been confirmed. The lead could be detected in small concentrations all over the catalyst but the highest concentrations were found in agglomerates/particles situated on the surface of the support ma- 


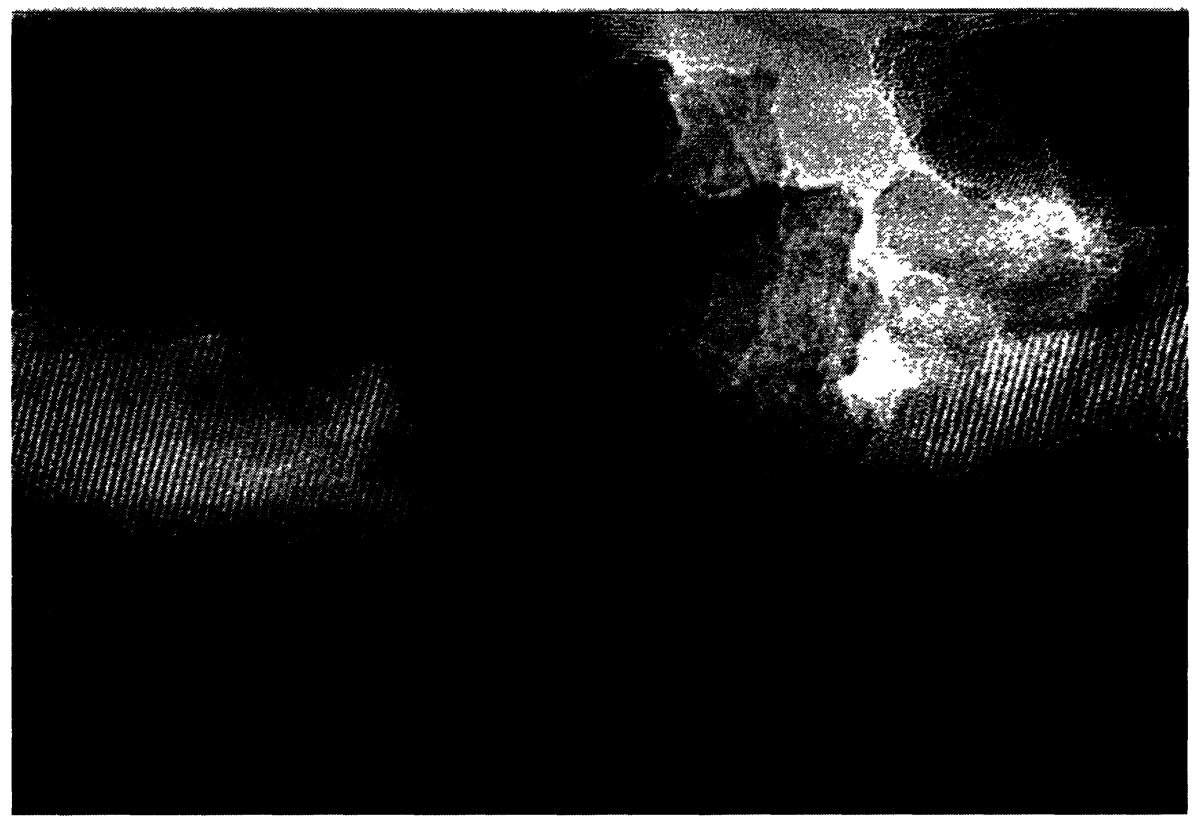

Fig. 5. - This kind of sintered of platinum and rhodium are frequently found in the used catalytic converter.
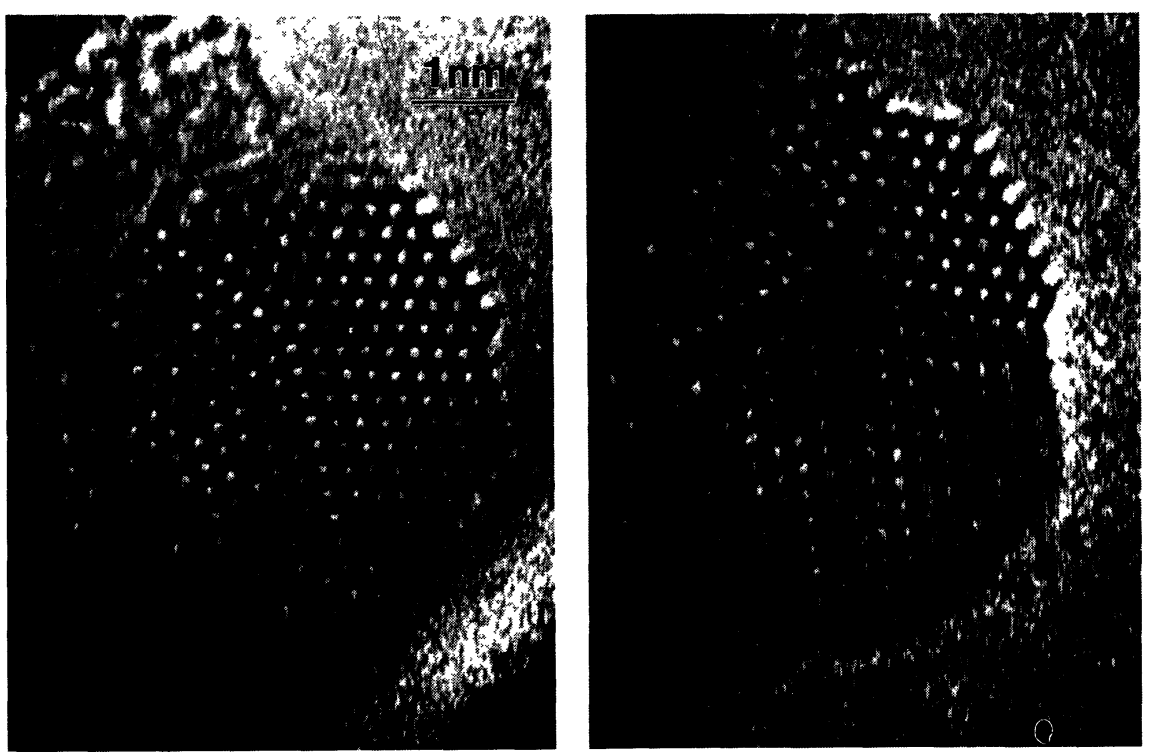

Fig. 6. - Small multiply twinned particle of one of the active metals ( $\mathrm{Pt}$ or $\mathrm{Rh}$ ) or of both. The left image shows a almost perfect decahedron while the particle has grown in the right image. An increased activity can be seen on one of the surface in the growth direction (arrow). The behaviour of this particle in the electron beam indicates that it consists of mainly platinum. 
terial. In these agglomerates the lead concentration in some cases could be close to 10 atomic\% and was usually at least 5 atomic\%. The EDS analyses show that the composition of the agglomerates/particles was, apart from lead, mainly aluminium and a few percent of nickel and cerium. This shows that the washcoat $\left(\mathrm{Al}_{2} \mathrm{O}_{3}\right.$ with traces of ceria) has been affected resulting in these contamination containing particles.

The active metals (Pt and $\mathrm{Rh}$ ) can be detected both as the initial small particles (though rare) and as large sintered particles. There is no evidence for lead affecting or taking part in the sintering process but small amounts of lead are frequently present in or in connection to the sintered particles. The sintered particles were in all cases composed of a mixture of platinum and rhodium. The $\mathrm{Rh} / \mathrm{Pt}$ ratio in commercial catalysts is usually kept low (typically 0.2 or less) but in the sintered particles the ratio found was usually higher, sometimes even over one. It was possible to image the small original particles in some rare cases. However the sulphur induced (100) faceting previously reported for platinum [8] was not observed in this study.

\section{Acknowledgements.}

This work was supported by The Swedish Natural Science Research Council and by The National Energy Administration of Sweden. The availibility of the JEM 2000FX and JEM 4000EX microscopes was made possible through grants from The Alice and Knut Wallenberg Foundation.

\section{References}

[1] O'Keefe M.A., BuSeck P., Trans. Am. Cryst. Assoc. 15 (1979) 27.

[2] STADELMANN P.A., Ultramicroscopy 21 (1987) 131.

[3] Malm J.-O., Bovin J.-O., Petford-LONG A.K., Schmid G., Klein N., Angew. Chem. Int. Ed. Eng. 27 (1988) 55.

[4] IIJIMA S., ICHIHASHI T., Phys. Rev. Lett. 56 (1986) 616.

[5] STENBOM B., SMEDleR G., NilsSON P.H., Lundgren S., WiRMaRK G., SAE Technical Paper Series, 900273 (1990).

[6] FIEDOROW R.M.J., ChAHAR B.S., WANKE S.E., J. Cat. 51 (1978) 193.

[7] White D., Baird T., Fryer J.R., SMith D.J., Inst. Phys. Conf. Ser. 61 (1981) 403.

[8] JEFFERSON D.A., HARRIS P.J.F., Nature 332 (1988) 617. 